\title{
Cross-cultural aspects of pregnancy and breast feeding
}

\section{By G. J. Ebrahim, Institute of Child Health, London}

More than three-quarters of humanity lives in the developing world and up to $80 \%$ of the population there lives in rural areas. In the. villages and hamlets of the Third World, the greater proportion of the world's babies are being born and brought up in the traditions and practices which have existed for many generations. In the past two decades a considerable investment in medical education and the expansion of health services has been made in all developing countries and yet only a few of them have been able to achieve the objective of universal health coverage. There are several reasons for this failure. Where maternity care is concerned much of it is likely to be due to not taking into account the customs and belief systems of the rural society.

Rituals and beliefs exist in varying forms in different societies, especially around the time of important milestones in the life cycle. We find birth and naming rituals, rituals marking the attainment of adulthood, weddings and funerals. These rituals have been described as the Rites of Passage in the anthropological ritual. The time of childbirth is associated with so much joy and at times so much of tragedy that it is not surprising that pregnancy and childbirth are at the centre of many customs, practices, and rituals.

When studying pregnancy and childbirth in the peasant society the most striking finding is the young age at marriage, which usually takes place around the onset of menarche. In some instances betrothal takes place even earlier, the young bride going to stay with the husband and his family after menarche. In Tanzania amongst the Wazaramo of the coastal region the average age of mothers at the time of the birth of their first baby is 16.6 years. In Hyderabad, India it is 16.2 years and the same is also true for rural Java. In some cultures there is a prior ceremony of initiation at puberty associated with the practice of the Pharonic circumcision. In all cases, however, there is a period of apprenticeship during which the older girl has been learning to care for her younger sibling.

In all traditional societies child-bearing is a social phenomenon, a part of everyday family life, and not a medical condition. Births occur within the family environment largely supported by friends, family members and kinsfolk. It is customary in many cultures for the pregnant woman to go to her mother's home to have her baby. It is always the village birth attendant who is consulted and not the medicine man or shaman. In several cultures pregnancy will be kept secret until the 7 th month to avoid the evil eye and this certainly creates problems with regard to antenatal care. In others, as in Java, pregnancy is announced early and celebrated with ceremonial feasts and rejoicings. 
The traditional society has learned to recognize pregnancy as a period of many risks because of the high perinatal and maternal mortality. Mishaps are ascribed to ancestral spirits who have been offended as is common in several tribal societies in tropical Africa. They may be due to non-observance of religious tenets, breaking of taboos or caused by evil spirits. For example, out of sixty-five cultures surveyed, thirty-eight were found to practice dietary restrictions of various types during pregnancy. Apart from food taboos, a close study of some of the rituals indicates that each of the components of a ritual encapsulates a practice beneficial for the infant or contributing to his care. For example, the practice of isolation of the mother and her infant for a defined period of time contributes to mother-infant bonding.

Due to the importance of the rituals, the elderly woman is the predominant assistant, with daughters, sisters, mother and mother-in-law as the natural helpers. In most cases, the birth attendant is a woman who is well known and familiar. In many cultures the traditional birth attendant inherits the function from her own mother or grandmother. For example, the wife of the village barber is commonly the birth attendant in rural India.

Birth takes place in a secluded room or in a part of the house set aside for it. Often friends and kinsfolk who have gathered sing birth songs to encourage the mother. Disposal of the placenta is of great importance because in many cultures it is considered the twin of the infant. It is usually buried near the home in great secrecy and often a tree is planted at the site.

Soon after delivery the newborn and the mother must go into strict seclusion. Doors and windows are kept shut to keep out the evil spirits and a great variety of precautions are taken to frighten them away. For example, a fire is kept smouldering near the door or various iron objects are kept near the mother and her baby. Only the birth attendant and very close family members are allowed to visit for brief periods. For most of the time the mother and her baby are thrown into each other's company during this period of seclusion which may vary from 7 to 40 days.

A variety of lactagogues are used together with many herbal medicines, both during childbirth and the puerperium. Some of these potions may be harmful or even dangerous. For example, extracts of herbs with oxytoxic action are known to cause the high incidence of uterine rupture and birth asphyxia amongst the Banganda. The Hausa of Northern Nigeria offer the parturient woman a pap containing the local lake salt, Kanwa. This adds a salt load of $13 \mathrm{~g}$ per day to the mean total intake of $6.4 \mathrm{~g}$ in the local diet. The very high incidence of post-partum cardiac failure and hypertension amongst the Hausa mothers is very likely related to this practice.

The birth attendant visits daily to massage the mother and wash the baby. She also advises with regard to the day-to-day care and feeding of the baby and provides considerable emotional support. In many ways she is mothering the mother and gives the necessary psychological support for this rather sensitive period. In recent anthropological literature this role of the birth attendant is being 
referred to as the 'doula' function and is considered crucial for the establishment of lactation. No wonder failure of lactation is such a rare phenomenon in many rural societies.

This description of the functions of the traditional birth attendant in the rural societies establishes her, without doubt, as the main provider of maternity care. When considering rapid expansion of maternity services on a national scale, it is more logical to think of her as an already existing resource and improve the quality of her services by training in practical aspects of nutrition, hygiene and early detection of at-risk mothers. The traditional birth attendant is more capable of carrying the message of health into the rural home than the city-based specialist. She will also be more effective in stopping some of the harmful practices.

Several countries have embarked on national programmes of improving rural maternity services through training birth attendants as in Sudan and Indonesia, or through the use of minimally trained auxiliaries as in Tanzania. Teaching pregnant women to consume an extra handful of rice or the staple during pregnancy, or to take iron and folic acid, or the use of simple hygienic procedures in childbirth as well as the importance of breast-feeding is so much more effective through locally known and trusted individuals compared to strangers from the city who visit periodically.

\section{BIBLIOGRAPHY}

Davidson, N. McD. \& Parry, E. H. O. (1978). Q. $\mathscr{f l}$ Med. New Series, XLVII, 188, 431 .

Ebrahim, G. J. (1976). In Breast feeding and the Mother. Ciba Foundation Symposium, No. 45 , p. 195. Holland: Elsevier.

Ebrahim, G. J. (1978). In Care of the Newborn in developing countries. Basingstoke: Macmillan Press.

Swantz, M. ( 1966 ). The religious and magical rites connected with the life cycle of the woman in some Bantu ethnic groups of Tanzania. Thesis for the Degree of Filosofian Lisensiatti, University of Turku, Finland.

Swantz, M. (1973). In The Young Child in Tanzania. Report of a Study under the auspices of the Tanzania National Scientific Research Council, p. $24 \mathrm{I}$.

van Gennep, A. (1964). Rites of Passage. Routledge \& Keegan Paul (Originally published in French in 1908). 